\title{
Usefulness of Electrocardiographic QRS/T angles With versus Without Bundle Branch Blocks to Predict Heart Failure (From the Atherosclerosis Risk in Communities [ARIC] Study)
}

\author{
Zhu-ming Zhang, MD, MPH ${ }^{\mathrm{a}}$, Pentti M. Rautaharju, MD, PhD ${ }^{\mathrm{a}}$, Ronald J. Prineas, MB, BS, \\ $\mathrm{PhD}^{\mathrm{a}}$, Laura Loehr, MD, PhD ${ }^{\mathrm{b}}$, Wayne Rosamond, $\mathrm{PhD}^{\mathrm{b}}$, and Elsayed Z. Soliman, MD, MSc, \\ MS $^{\mathrm{a}, \mathrm{c}}$ \\ aEpidemiological Cardiology Research Center (EPICARE), Department of Epidemiology and \\ Prevention, Division of Public Health Sciences, Wake Forest School of Medicine, Winston-Salem, \\ North Carolina \\ bDepartment of Epidemiology, Galling's School of Global Public Health, University of North \\ Carolina at Chapel Hill, Chapel Hill, North Carolina \\ 'Department of Internal Medicine, Section of Cardiology, Wake Forest School of Medicine, \\ Winston-Salem, North Carolina
}

\begin{abstract}
Repolarization abnormalities in the setting of bundle branch blocks (BBB) are generally ignored. We used Cox regression models to determine hazard ratios (HR) with 95\% confidence intervals (CI) for incident heart failure (HF) associated with wide spatial and frontal QRS/T angle (upper $25^{\text {th }}$ percentile of each) in men and women with and without BBB. This analysis included 14,478 participants (54.6\% women, 26.4\% blacks, 377 (2.6\%) with BBB) from the Atherosclerosis Risk in Communities Study who were free of HF at baseline. Using No-BBB with normal spatial QRS/T angle as the reference group, the risk for HF in multivariable adjusted models was increased 51\% for No-BBB with wide spatial QRS/T angle (HR 1.51, CI 1.37-1.66), 48\% for BBB with normal spatial QRS/T angle (HR 1.48, CI 1.17-1.88), and the risk for incident HF was increased over 3-fold for BBB with wide spatial QRS/T angle (HR 3.37, CI 2.47-4.60). The results were consistent across subgroups by sex. Similar results were observed for the frontal plane QRS/T angle. In the pooled BBB group excluding RBBB, a positive $T$ wave in lead aVR and heart rate $70 \mathrm{bpm}$ and higher were also potent predictors of incident HF similar to the QRS/T angles. In conclusion, both $\mathrm{BBB}$ and wide $\mathrm{QRS} / \mathrm{T}$ angles are predictive of heart failure, and concomitant presence of both carries a much higher risk than for either predictor alone. These findings suggest
\end{abstract}

(C) 2014 Excerpta Medica, Inc. All rights reserved.

Correspondence, Zhu-Ming Zhang, MD, MPH, Epidemiological Cardiology Research Center (EPICARE), Department of Epidemiology and Prevention, Division of Public Health Sciences, Wake Forest School of Medicine, Medical Center Blvd. WinstonSalem, NC 27157 U.S.A. Phone: (336)716-0835 Fax: (336) 716-0834 zmzhang@ wakehealth.edu.

Publisher's Disclaimer: This is a PDF file of an unedited manuscript that has been accepted for publication. As a service to our customers we are providing this early version of the manuscript. The manuscript will undergo copyediting, typesetting, and review of the resulting proof before it is published in its final citable form. Please note that during the production process errors may be discovered which could affect the content, and all legal disclaimers that apply to the journal pertain.

Disclosures The authors have no conflicts of interests to disclose. 
that repolarization abnormalities in the setting of $\mathrm{BBB}$ should not be considered benign or an expected consequence of BBB.

\section{Keywords}

electrocardiography; bundle branch block; QRS/T angle; heart failure

\section{Introduction}

Abnormal electrocardiographic (ECG) repolarization markers such as wide spatial and frontal QRS-T angle have been repeatedly shown to be predictive of cardiovascular disease (CVD) events including incident heart failure (HF). ${ }^{1-14}$ Most of these previous studies, however, excluded participants with bundle branch blocks (BBBs). Hence, there is a paucity of information on the prognostic significance of repolarization abnormalities in the setting of BBBs. The aim of the present study is to evaluate the independent prognostic significance for the QRS/T angle and other ECG measures of abnormal repolarization for the prediction of incident HF in individuals with and without BBB.

\section{Methods}

This analysis included participants from the Atherosclerosis Risk In Communities (ARIC) Study, a population-based multicenter prospective study of blacks and whites designed to investigate the natural history and cause of atherosclerotic and cardiovascular disease from 4 US communities: Forsyth County, North Carolina; Jackson, Mississippi; suburbs of Minneapolis, Minnesota; and Washington County, Maryland ( $\mathrm{n}=15,792$ men and women aged 45 to 64 years). Eligible participants were interviewed at home and then invited to a baseline clinical examination between 1987 and 1989. They attended 3 additional clinical examinations at 3 -year intervals and a recent $5^{\text {th }}$ examination completed in 2013 for which data is not included here. Participants were interviewer by phone annually. Details of the ARIC Study design, protocol sampling procedures, and selection and exclusion criteria were published elsewhere. ${ }^{15}$ The study was approved by each study site's institutional review board. All participants provided written informed consent. For the purpose of this analysis, we excluded 1,314 participants: 405 with missing ECG or key variables, 126 with inadequate quality ECG or ECG diagnosis of external pacemaker or Wolff-Parkinson-White pattern, 44 with race other than black or white, and 739 with prevalent HF at baseline. After all exclusions, 14,478 participants, of whom 377 had BBB, remained and were included in this analysis.

Incident HF occurred from baseline through December 31, 2010 was considered in the present investigation. The follow-up period was up to 24 years (mean 21 years). Incident HF was defined by International Classification of Disease (ICD) codes as the first occurrence of either a hospitalization with a HF hospital discharge diagnosis code (ICD- ${ }^{\text {th }}$ Revision, Clinical Modification, code 428), or a death certificate with any listing of a 428 ICD-9 code or code I50 ICD-10 code. Detailed definitions for incident HF classification were published previously. ${ }^{15-17}$ 
Identical electrocardiographs (MAC PC, Marquette Electronics Inc., Milwaukee, Wisconsin) were used at all clinic sites, and resting, 10-second standard simultaneous 12-lead ECGs were recorded in all participants using strictly standardized procedures. All ECGs were processed in a central ECG laboratory (initially at Dalhousie University, Halifax, NS, Canada and later at the EPICARE Center, Wake Forest School of Medicine, Winston-Salem, $\mathrm{NC}$ ), where all ECGs were visually inspected for technical errors and inadequate quality using an interactive computer graphics terminal. The ECGs were first processed by the Dalhousie ECG program and were reprocessed for the present study using the 2001 version of the GE Marquette 12-SL program (GE, Milwaukee, Wisconsin). Different patterns of BBB were classified according to the Minnesota Code (MC) criteria as follows: ${ }^{18}$ complete left BBB (LBBB, MC-7.1), complete right (RBBB, MC-7.2, QRS axis >-45 degree), intraventricular conduction defect (IVCD, MC-7.4), and combination of RBBB and left anterior fascicular block (LAFB) (MC-7.8, RBBB and QRS axis between -45 and -120 degree). Global interval measurements were obtained from the quasiorthogonal XYZ leads computed from the standard 12-lead ECGs using the Horácek transform. ${ }^{19}$ Spatial QRS/T angle was derived as the angle between the mean QRS and T vectors. Frontal plane QRS/T angle was defined as the absolute value of the difference between the frontal plane QRS axis and frontal plane $\mathrm{T}$ axis and was adjusted to the minimal angle using $\left(360^{\circ}\right.$ - angle) for an angle $>180^{\circ}$ (axis measure range from $-89^{\circ}$ to $+270^{\circ}$ in the GE-Marquette ECG program). ${ }^{6}$ ECG left ventricular hypertrophy (ECG-LVH) was defined by modified Cornell voltage (RaVL+SV3). ${ }^{20}$ Rate-adjusted QT interval (QTa) was computed as a linear function of the RR interval with separate formulas derived for women or men, and with or without BBB.

In our previous report on BBB and HF among postmenopausal women, STJ-aVL amplitude in LBBB and STJ-aVL and T-aVR amplitudes in a No-LBBB group were found to be significant predictors of HF in addition to Quintile 5 of QRS/T angle. ${ }^{14}$ Therefore, it was decided to include STJ and T wave amplitudes from 3 quasiorthogonal standard leads (V6, $\mathrm{aVR}$ and V1) as additional repolarization variables in some of the analyses of the present study.

Frequency distributions of ECG measurements were inspected to identify anomalies and outliers. Descriptive statistics were used to determine mean values, standard deviations, and percentile distributions for continuous variables, and frequencies and percentages for categorical variables. Cox's proportional hazards regression was used to assess the associations of ECG measures with the risk of HF: model-1 for unadjusted; model-2 adjusted for demographics (age, sex, and race); and model-3 adjusted for demographic, regional center, body mass index, systolic blood pressure, smoking status, hypertension, diabetes mellitus, history of CVD status, ratio of total cholesterol/ high-density lipoprotein, blood glucose, serum creatinine, and ECG QRS duration at baseline, which were potential confounders and could impact on QRST angle. The risk for incident HF in BBB was first evaluated with $\mathrm{QRS} / \mathrm{T}$ angles as continuous variables. It was observed that the risk for frontal plane QRS/T angle started increasing approximately at 75th percentile and that for spatial QRS/T angle at 50th percentile. It was decided to determine the risk for HF for QRS/T angles with quartile 4 as the test group and quartiles 1-3 in the No-BBB as the reference group (Supplementary 1). Hazard ratios (HR) were evaluated for increased values of ECG predictor variables (quartile 4) with quartiles 1-3 as the reference group (HR $=1)$. 
However, quartiles 1 (decreased or more negative values) was used as the test group for $\mathrm{T}$ wave amplitude and ST J-point depression in lead V6, with quartiles 2-4 as the reference group. All analyses were performed with SAS version 9.3 (SAS Institute Inc., Cary, North Carolina).

\section{Results}

The mean age at baseline was 54 years, 54.6\% were women, 26.4\% African American, and $5.2 \%$ had a history of CVD or ECG evidence of MI. BBB was present in 2.6\%. Details of demographic, clinical, and ECG characteristics of the study population are summarized in Table 1.There were statistically significant differences between test group and reference group by spatial QRS/T angle, and No-BBB group and BBB group in most of the demographic, clinical characteristics and ECG measurements ( $\mathrm{P}<0.05$ or less).

The correlation between spatial and frontal plane QRS/T angle was 0.464 in the No-BBB group and 0.648 in the BBB group (Supplementary 2). The correlations for T wave amplitude in aVR, V1, and V6 with spatial QRS/T angle were also listed respectively.

During an average of 21 years follow-up, 2,329 were hospitalized for incident HF. The event rates of incident $\mathrm{HF}$ for different outcomes by dichotomized QRS/T angle categories were shown in Table 2. In multivariable adjusted models and compared to No-BBB with normal spatial QRS/T angle, BBB with normal QRS/T angle and wide QRS/T angle without BBB were associated with $48 \%$ and $51 \%$ increased risk of heart failure. In addition, presence of both BBB and wide spatial QRS/T angle was associated with over 3-fold risk of incident HF. Similar results were observed for the frontal plane QRS/T angle. Survival curves for subgroups by dichotomized spatial QRS/T angles in No-BBB and BBB groups are graphed in Figures 1-2 for incident HF further highlighting the trends shown in Table 2. No interaction was observed by sex, and the results were consistent in men and women (Table $3)$.

Table 4 shows the results for the risk of incident HF separately for RBBB and the rest of the BBBs combined for the spatial QRS/T angle, the frontal plane QRS/T angle and selected other repolarization variables as predictors. To secure equal size test groups for each variable evaluated in this table, quartile 4 was used as the test group and quartiles 1-3 as the reference group for each. The risk for incident HF in the pooled BBB group was increased over 2-fold for spatial QRS/T angle and over 3-fold for frontal plane QRS/T angle. For other repolarization-related variables, the risks of incident $\mathrm{HF}$ for a positive $\mathrm{T}$ amplitude in lead aVR and heart rate $70 \mathrm{bpm}$ or higher were as high as for the spatial QRS/T angle (over 2fold). The right section in Table 4 shows the risk for incident HF for RBBB, where only the frontal plane QRS/T angle significantly increased risk over 2-fold for incident HF.

\section{Discussion}

We evaluated the prognostic value for wide QRS/T angle and other ECG measures of abnormal repolarization in men and women with No BBB and with BBB. The key findings are: 1) $\mathrm{BBB}$ and wide $\mathrm{QRS} / \mathrm{T}$ angle as well as other repolarization markers are predictive of incident HF; 2) Concomitant presence of both BBB and wide QRS/T angle carries a much 
higher risk of incident HF than either one alone; 3) In the pooled BBB group excluding RBBB, a positive $T$ aVR and heart rate $70 \mathrm{bpm}$ and higher were as potent predictors of incident $\mathrm{HF}$ as the $\mathrm{QRS} / \mathrm{T}$ angles. These findings suggest that repolarization abnormalities in the setting of BBB should not be considered as an innocent consequence of the BBB.

In normal ventricular depolarization and repolarization, the spatial direction of repolarization in the left lateral wall is predominantly reversed with respect to the direction of depolarization. The ECG spatial QRS/T is an angle between the spatial axes of ventricular depolarization and repolarization. QRS/T angle reflects changes in the direction of the repolarization sequence. Delayed left ventricular excitation and contraction in BBB leads into dyssynchrony of ventricular contraction and also leads into delayed left ventricular repolarization and relaxation. A wide QRS/T angle represents a larger discordance between depolarization and repolarization. ${ }^{21-23}$

Many studies in men and women with normal ventricular conduction have documented that LBBB is a significant predictor of HF. ${ }^{24-26}$ These studies have in general found that the risk for RBBB is not significant or only marginally significant. ${ }^{13,27-28}$ It has been suggested that the QRS/T angle should be a part of the ECG evaluation of the patient with HF. ${ }^{2-14}$ Frontal $\mathrm{QRS} / \mathrm{T}$ angle is an alternative to the spatial QRS/T angle as an easily calculated parameter from frontal plane QRS and T axis available from computer-ECG reports. ${ }^{6-11}$ Zhang et al. evaluated the association of BBB and the risk of incident HF during 14 year follow-up in 65,975 participants in the Women's Health initiative. ${ }^{14}$ The results showed that a pooled BBB groups including LBBB, IVCD, and RBBB combined with LAFB was a strong predictors of incident $\mathrm{HF}$ in multivariable adjusted risk models. Our results expand this by showing that the association becomes even stronger in case of concomitant presence of BBB and widened QRS/T angle.

Tan et al. in a large study group of male veterans without BBB or arrhythmias found a positive TaVR associated with increased risk of CVD deaths. ${ }^{29}$ In a report by Anttila et al. using data of a large group of men and women representative of general population of adults in a health examination survey in Finland, a flat or positive T wave (prevalence 2.4\%) was a strong predictor of CVD mortality in multivariable adjusted risk models. ${ }^{30} \mathrm{In}$ our previous study in CVD-free men and women, TaVR was an independent predictor of CHD death with an over 2 -fold increased risk. ${ }^{5}$ The present study extended these observations and demonstrated that in the pooled BBB group excluding RBBB a positive TaVR was associated with an over 2-fold risk of incident HF.

\section{Supplementary Material}

Refer to Web version on PubMed Central for supplementary material.

\section{Acknowledgments}

The ARIC Study is carried out as a collaborative study supported by National Heart, Lung, and Blood Institute contracts (HHSN268201100005C, HHSN268201100006C, HHSN268201100007C, HHSN268201100008C, HHSN268201100009C, HHSN268201100010C, HHSN268201100011C, and HHSN268201100012C). The authors thank the staff and participants of the ARIC study for their important contributions. 


\section{References}

1. Kors JA, de Bruyne MC, Hoes AW, van HG, Hofman A, van Bemmel JH, Grobbee DE. T axis as an indicator of risk of cardiac events in elderly people. Lancet. 1998; 352:601-605. [PubMed: 9746020]

2. Yamazaki T, Froelicher VF, Myers J, Chun S, Wang P. Spatial QRS-T angle predicts cardiac death in a clinical population. Heart Rhythm. 2005; 2:73-78. [PubMed: 15851268]

3. Rautaharju PM, Kooperberg C, Larson JC, LaCroix A. Electrocardiographic predictors of incident congestive heart failure and all-cause mortality in postmenopausal women: the Women's Health Initiative. Circulation. 2006; 113:481-489. [PubMed: 16449727]

4. Rautaharju PM, Zhang ZM, Haisty WK, Prineas RJ, Kucharska-Newton AM, Rosamond W, Soliman EZ. Electrocardiographic Predictors of Incident Heart Failure in Men and Women Free from Manifest Cardiovascular Disease in the Atherosclerosis Risk in Communities (ARIC) Study. Am J Cardiol. 2013; 112:843-849. [PubMed: 23768456]

5. Rautaharju PM, Zhang ZM, Warren J, Gregg RE, Haisty WK Jr, Kucharska-Newton AM, Rosamond WD, Soliman EZ. Electrocardiographic Predictors of coronary heart disease and sudden cardiac deaths in men and women free from cardiovascular disease in the Atherosclerosis Risk in Communities (ARIC) Study. J Am Heart Assoc. 2013; 2:e000061. [PubMed: 23723252]

6. Zhang ZM, Prineas RJ, Case D, Soliman EZ, Rautaharju PM. for the ARIC Research Group. Comparison of the prognostic significance of the electrocardiographic QRS/Tangles in predicting incident coronary heart disease and total mortality (from the atherosclerosis risk in communities study). Am J Cardiol. 2007; 100:844-849. [PubMed: 17719331]

7. Borleffs CJ, Scherptong RW, Man SC, van Welsenes GH, Bax JJ, van Erven L, Swenne CA, Schalij MJ. Predicting ventricular arrhythmias in patients with ischemic heart disease: clinical application of the ECG-derived QRS-T angle. Circ Arrhythm Electrophysiol. 2009; 2:548-554. [PubMed: 19843923]

8. Walsh JA 3rd, Soliman EZ, Ilkhanoff L, Ning H, Liu K, Nazarian S, Lloyd-Jones DM. Prognostic value of frontal QRS-T angle in patients without clinical evidence of cardiovascular disease (from the Multi-Ethnic Study of Atherosclerosis). Am J Cardiol. 2013; 112:1880-1884. [PubMed: 24063831]

9. Whang W, Shimbo D, Levitan EB, Newman JD, Rautaharju PM, Davidson KW, Muntner P. Relations between QRS|T angle, cardiac risk factors, and mortality in the third National Health and Nutrition Examination Survey (NHANES III). Am J Cardiol. 2012; 109:981-987. [PubMed: 22221946]

10. Lown MT, Munyombwe T, Harrison W, West RM, Hall CA, Morrell C, Jackson BM, Sapsford RJ, Kilcullen N, Pepper CB, Batin PD, Hall AS, Gale CP. Evaluation of Methods and Management of Acute Coronary Events (EMMACE) Investigators. Association of frontal QRS-T angle--age risk score on admission electrocardiogram with mortality in patients admitted with an acute coronary syndrome. Am J Cardiol. 2012; 109:307-313. [PubMed: 22071208]

11. Gotsman I, Keren A, Hellman Y, Banker J, Lotan C, Zwas DR. Usefulness of electrocardiographic frontal QRS-T angle to predict increased morbidity and mortality in patients with chronic heart failure. Am J Cardiol. 2013; 15(111):1452-1459. [PubMed: 23453457]

12. Dawood FZ, Khan F, Rofediger MP, Zhang ZM, Swaminathan S, Klinker H, Hoy J, Lundgren JD, Neaton JD, Soliman EZ. Electrocardiographic Spatial QRS-T Angle and Incident Cardiovascular Disease in HIV-Infected Individuals (From the Strategies for the Management of Antiretroviral Therapy [SMART] Study). Am J Cardiol. 2013; 111:118-124. [PubMed: 23062314]

13. Zhang ZM, Rautaharju PM, Soliman EZ, Manson JE, Cain ME, Martin LW, Bavry AA, Mehta L, Vitolins M, Prineas RJ. Mortality risk associated with bundle branch blocks and related repolarization abnormalities (from the Women's Health Initiative [WHI]). Am J Cardiol. 2012; 110:1489-1495. [PubMed: 22858187]

14. Zhang ZM, Rautaharju PM, Soliman ES, Manson JE, Martin LW, Perez M, Vitolins M, Prineas RJ. Different Patterns of Bundle Branch Blocks and the Risk of Incident Heart Failure in the Women's Health Initiative (WHI) Study. Circ Heart Fail. 2013; 6:655-661. [PubMed: 23729198]

15. ARIC Investigators. The Atherosclerosis Risk in Communities (ARIC) Study: design and objectives. Am J Epidemiol. 1989; 129:687-702. [PubMed: 2646917] 
16. Rosamond WD, Chang PP, Baggett C, Johnson A, Bertoni AG, Shahar E, Deswal A, Heiss G, Chambless LE. Classification of heart failure in the atherosclerosis risk in communities (ARIC) study: a comparison of diagnostic criteria. Circ Heart Fail. 2012; 5:152-159. [PubMed: 22271752]

17. Rautaharju PM, Prineas RJ, Wood J, Zhang ZM, Crow R, Heiss G. Electrocardiographic predictors of new-onset heart failure in men and in women free of coronary heart disease (from the Atherosclerosis in Communities [ARIC] Study). Am J Cardiol. 2007; 100:1437-1441. [PubMed: 17950804]

18. Prineas, RJ.; Crow, RS.; Zhang, ZM. The Minnesota code manual of electrocardiographic findings. Second edition. Published by Springer-London; 2010. p. 16-166.

19. Kors JA, van Herpen G, Sittig AC, van Bemmel JH. Reconstruction of the Frank vectorcardiogram from standard electrocardiographic leads: diagnostic comparison of different methods. Eur Heart J. 1990; 11:1083-1092. [PubMed: 2292255]

20. Rautaharju PM, Park LP, Chaitman BR, Rautaharju F, Zhang ZM. The Novacode criteria for classification of ECG abnormalities and their clinically significant progression and regression. $\mathrm{J}$ Electrocardiol. 1998; 31:157-187. [PubMed: 9682893]

21. Goldenberg I, Moss AJ, Hall WJ, Foster E, Goldberger JJ, Santucci P, Shinn T, Solomon S, Steinberg JS, Wilber D, Barsheshet A, McNitt S, Zareba W, Klein H. MADIT-CRT Executive Committee. Predictors of response to cardiac resynchronization therapy in the multicenter automatic defibrillator implantation trial with cardiac resynchronization therapy (MADIT-CRT). Circulation. 2011; 124:1527-1536. [PubMed: 21900084]

22. Lam CS, Lyass A, Kraigher-Krainer E, Massaro JM, Lee DS, Ho JE, Levy D, Redfield MM, Pieske BM, Benjamin EJ, Vasan RS. Cardiac dysfunction and noncardiac dysfunction as precursors of heart failure with reduced and preserved ejection fraction in the community. Circulation. 2011; 124:24-30. [PubMed: 21670229]

23. Zhu TG, Patel C, Martin S, Quan X, Wu Y, Burke JF, Chernick M, Kowey PR, Yan GX. Ventricular transmural repolarization sequence: its relationship with ventricular relaxation and role in ventricular diastolic function. Eur Heart J. 2009; 30:372-380. [PubMed: 19147608]

24. Eriksson P, Wilhelmsen L, Rosengren A. Bundle-branch block in middle-aged men: risk of complications and death over 28 years. The Primary Prevention Study in Göteborg, Sweden. Eur Heart J. 2005; 26:2300-2306. [PubMed: 16214833]

25. Lewinter C, Torp-Pedersen C, Cleland JG, Køber L. Right and left bundle branch block as predictors of long-term mortality following myocardial infarction. Eur J Heart Fail. 2011; 13:1349-1354. [PubMed: 22027083]

26. Haataja P, Nikus K, Kähönen M, Huhtala H, Nieminen T, Jula A, Reunanen A, Salomaa V, Sclarovsky S, Nieminen MS, Eskola M. Prevalence of ventricular conduction blocks in the resting electrocardiogram in a general population: The Health 2000 Survey. Int J Cardiol. 2013; 167:1953-1960. [PubMed: 22640691]

27. Fleg JL, Das DN, Lakatta E. Right bundle branch block: long-term prognosis in apparently healthy men. J Am Coll Cardiol. 1983; 1:887-892. [PubMed: 6826977]

28. Bussink BE, Holst AG, Jespersen L, Deckers JW, Jensen GB, Prescott E. Right bundle branch block: prevalence, risk factors, and outcome in the general population: results from the Copenhagen City Heart Study. Eur Heart J. 2013; 34:138-146. [PubMed: 22947613]

29. Tan SY, Engel G, Myers J, Sandri M, Froelicher VF. The prognostic value of T wave amplitude in lead aVR in males. Ann Noninvasive Electrocardiol. 2008; 13:113-119. [PubMed: 18426436]

30. Anttila I, Nikus K, Nieminen T, Jula A, Salomaa V, Reunanen A, Nieminen MS, Lehtimãki T, Virtanen V, Kãhõnen M. Relation of positive T wave in lead aVR to risk of cardiovascular mortality. Am J Cardiol. 2011; 108:1735-1740. [PubMed: 21906704] 


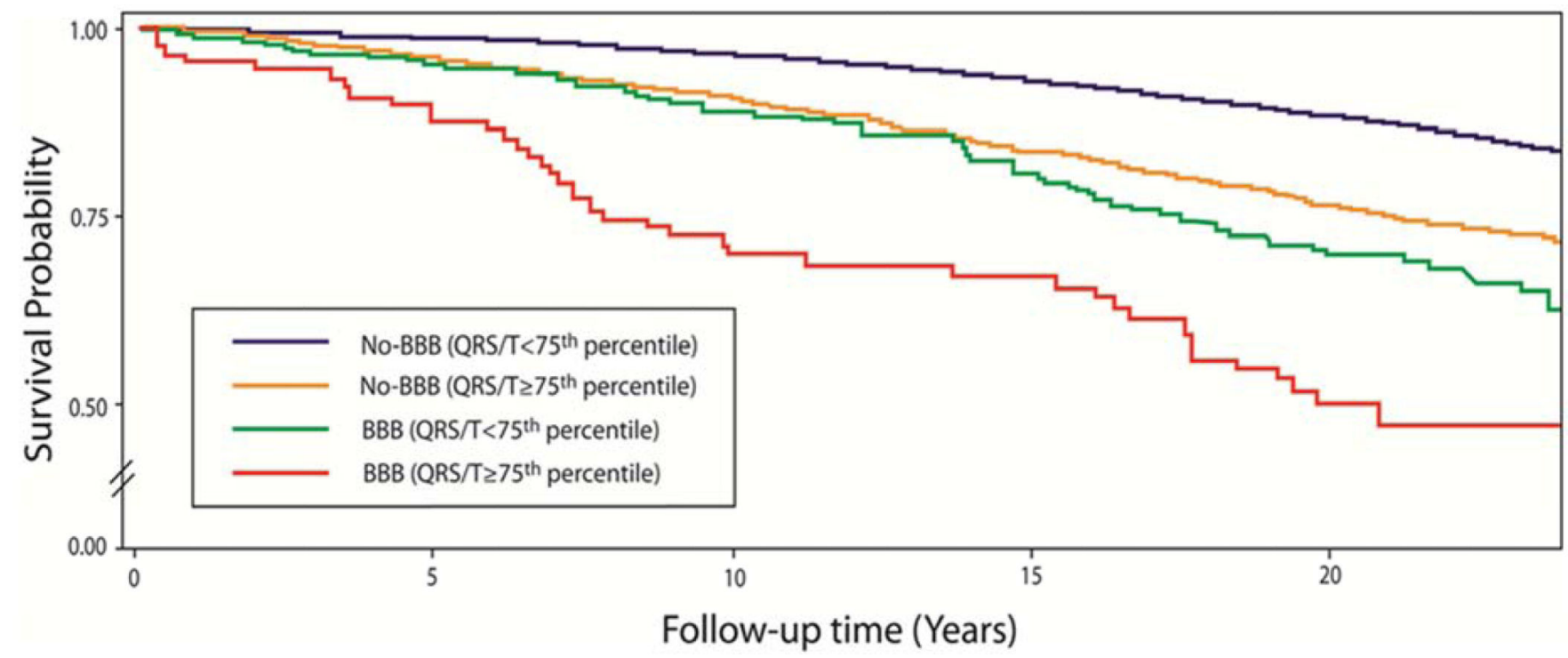

Figure 1.

Incident heart failure-free survival probability curves for no-bundle branch blocks (NoBBB) and for bundle branch blocks (BBB) with spatial QRS/T angle $<75^{\text {th }}$ and $\geq 75^{\text {th }}$ percentile, respectively. 


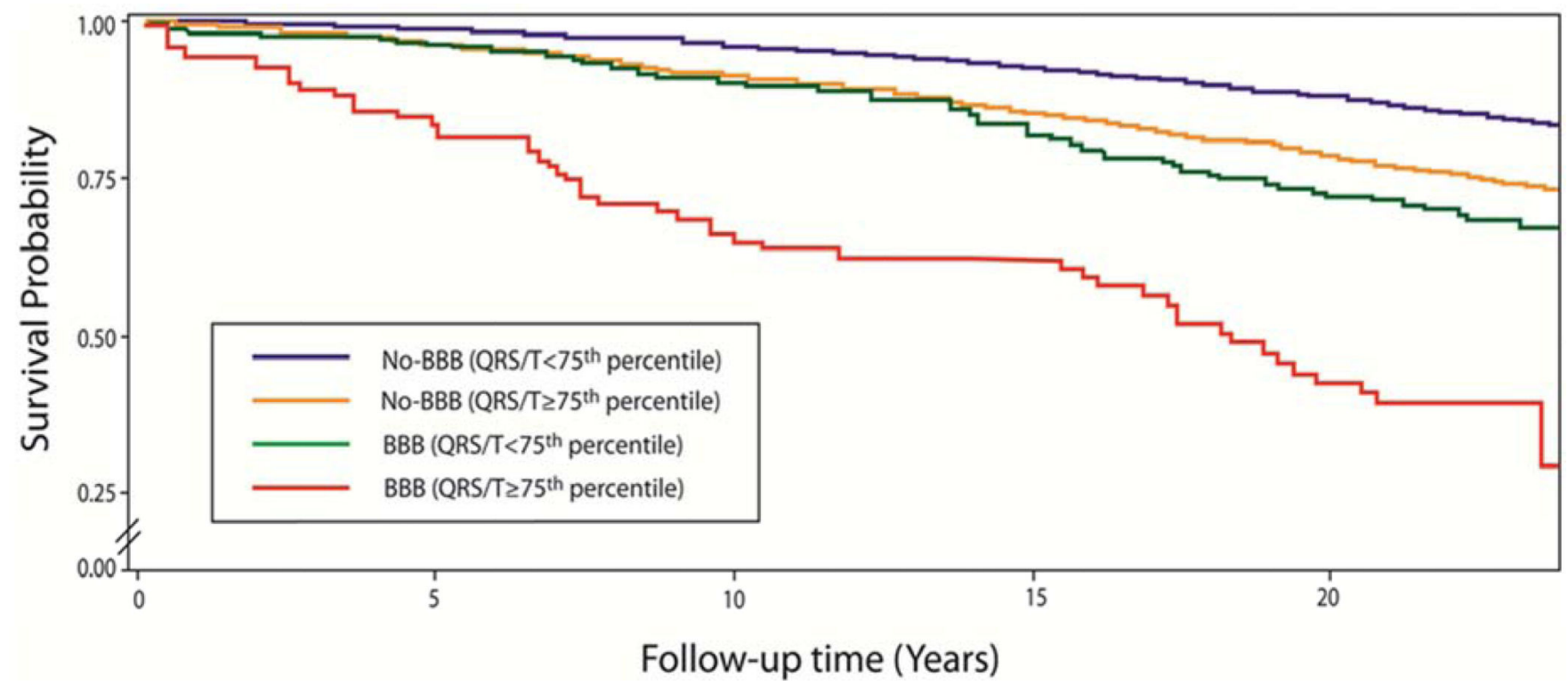

Figure 2.

Incident heart failure-free survival probability curves for no-bundle branch blocks (NoBBB) and for bundle branch blocks (BBB) with frontal QRS/T angle $<75^{\text {th }}$ and $\geq 75^{\text {th }}$ percentile, respectively. 
Table 1

Characteristic of study participants by bundle branch block and spatial QRS/T angle groups at baseline in the ARIC study (1987-1989) $(\mathrm{N}=14,478)$

\begin{tabular}{|c|c|c|c|c|}
\hline \multirow[b]{3}{*}{ Variable } & \multicolumn{4}{|c|}{ Bundle Branch Block } \\
\hline & \multicolumn{2}{|c|}{ No } & \multicolumn{2}{|c|}{ Yes } \\
\hline & $\begin{array}{c}\mathrm{QRS} / \mathrm{T}<7^{\text {th }} \\
(\mathrm{n}=10,576)\end{array}$ & $\underset{(\mathrm{n}=\mathbf{3 , 5 2 5})}{\mathrm{QRS} / \mathrm{T} \mathbf{7 5}^{\text {th }}}$ & $\underset{(\mathrm{n}=283)}{\mathrm{QRS} / \mathrm{T} \geq 5^{\text {th }}}$ & $\underset{(\mathrm{n}=94)}{\mathrm{QRS} / \mathrm{T}<\mathbf{7 5}^{\text {th }}}$ \\
\hline Age (years) & $54 \pm 6$ & $54 \pm 6^{\S}$ & $56 \pm 6$ & $58 \pm 5^{\dagger}$ \\
\hline Body mass index $\left(\mathrm{kg} / \mathrm{m}^{2}\right)$ & $28 \pm 5$ & $28 \pm 5$ & $28 \pm 5$ & $27 \pm 4$ \\
\hline Systolic blood pressure (mmHg) & $119 \pm 17$ & $126 \pm 22 \S$ & $124 \pm 21$ & $126 \pm 20$ \\
\hline Women & $61.2 \%$ & $37.2 \% \S$ & $28.6 \%$ & $42.6 \%{ }^{\dagger}$ \\
\hline African-American & $25.4 \%$ & $29.5 \% \S$ & $27.6 \%$ & $19.2 \%$ \\
\hline Education $\leq$ high school & $54.9 \%$ & $56.8 \% \S$ & $60.4 \%$ & $66.0 \%$ \\
\hline Current smoker & $24.0 \%$ & $31.6 \% \S$ & $29.0 \%$ & $23.4 \%$ \\
\hline Hypertension & $29.7 \%$ & $41.0 \% \S$ & $37.5 \%$ & $47.9 \%$ \\
\hline Diabetes mellitus & $9.4 \%$ & $15.7 \% \S$ & $14.2 \%$ & $17.0 \%$ \\
\hline History of CVD* & $3.4 \%$ & $9.5 \% \S$ & $15.9 \%$ & $22.3 \%$ \\
\hline Antihypertensive therapy & $25.8 \%$ & $30.7 \% \S$ & $34.3 \%$ & $51.1 \%$ \\
\hline \multicolumn{5}{|l|}{ ECG Characteristics } \\
\hline Spatial QRS/T angle ${ }^{\#}\left({ }^{\circ}\right)$ & $56 \pm 18$ & $107 \pm 18^{\S}$ & $91 \pm 29$ & $154 \pm 10^{\S}$ \\
\hline Frontal QRS/T angle $I l\left({ }^{\circ}\right)$ & $20 \pm 17$ & $41 \pm 38^{\S}$ & $44 \pm 35$ & $113 \pm 49 \S$ \\
\hline QRS axis $\left({ }^{\circ}\right)$ & $33 \pm 29$ & $23 \pm 39 \S$ & $15 \pm 51$ & $-4 \pm 51^{\frac{f}{f}}$ \\
\hline $\mathrm{T}$ axis $\left({ }^{\circ}\right)$ & $37 \pm 22$ & $43 \pm 48^{\S}$ & $29 \pm 35$ & $92 \pm 75^{\S}$ \\
\hline Heart rate (beats/min) & $66 \pm 10$ & $67 \pm 11^{\S}$ & $63 \pm 11$ & $67 \pm 10^{t}$ \\
\hline QRS duration (ms) & $90 \pm 9$ & $95 \pm 10^{\S}$ & $134 \pm 14$ & $143 \pm 16^{\S}$ \\
\hline $\mathrm{QT}_{\mathrm{a}} \# \#(\mathrm{~ms})$ & $415 \pm 16$ & $417 \pm 16^{\S}$ & $441 \pm 17$ & $446 \pm 17^{\dagger}$ \\
\hline \multicolumn{5}{|l|}{ STJ-point amplitude $(\mu \mathrm{V})$} \\
\hline Lead aVR & $-24 \pm 22$ & $-10 \pm 22^{\S}$ & $-13 \pm 22$ & $15 \pm 30^{\S}$ \\
\hline Lead V1 & $2 \pm 30$ & $23 \pm 34^{\S}$ & $47 \pm 45$ & $117 \pm 70^{\S}$ \\
\hline Lead V6 & $22 \pm 25$ & $5 \pm 25^{\S}$ & $7 \pm 28$ & $-17 \pm 37 \S$ \\
\hline \multicolumn{5}{|l|}{ T-wave amplitude $(\mu \mathrm{V})$} \\
\hline Lead aVR & $-226 \pm 81$ & $-140 \pm 103^{\S}$ & $-206 \pm 106$ & $-30 \pm 130^{\S}$ \\
\hline Lead V1 & $35 \pm 133$ & $168 \pm 143 \S$ & $-19 \pm 262$ & $390 \pm 337 \S$ \\
\hline Lead V6 & $240 \pm 115$ & $120 \pm 135^{\S}$ & $199 \pm 156$ & $-58 \pm 162^{\S}$ \\
\hline ECG-LVH by CV $\mathrm{CH}^{+t}$ & $0.6 \%$ & $5.7 \% \S$ & & \\
\hline Right bundle branch block & & & $51.6 \%$ & $13.8 \% \S$ \\
\hline Other BBB categories & & & $48.4 \%$ & $86.2 \% \S$ \\
\hline
\end{tabular}


${ }^{\dagger}$ Denotes $\mathrm{P}<0.05$;

${ }^{\ddagger} \mathrm{P}<0.01$;

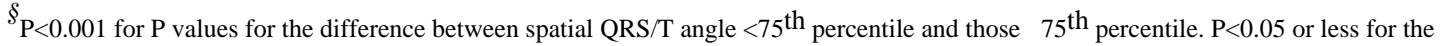
differences between No-BBB group and BBB group in almost of the variables except race $(\mathrm{P}=0.681)$.

* History of cardiovascular disease (CVD)=classified by ECG evidence of myocardial infarction according to the Minnesota Code or the NOVACODE criteria, or a self-reported history of a clinical diagnosis of myocardial infarction, angina pectoris, coronary artery bypass surgery, coronary angioplasty, heart failure, or stroke at the time entered study.

\# $\mathrm{QRS} / \mathrm{T}$ angle-Spatial plane= spatial angle between the mean QRS and ST-T vectors.

${ }^{\text {Il }} \mathrm{QRS} / \mathrm{T}$ angle-Frontal plane $=$ the absolute value of the difference between frontal plane QRS axis and frontal plane $\mathrm{T}$ axis. using $\left(360^{\circ}\right.$ - angle) for an angle $>180^{\circ}$ (axis measurement range from $-89^{\circ}$ to $+270^{\circ}$ in the GE-Marquette ECG program)

${ }^{\# \#} \mathrm{QTa}=\mathrm{QT}$ adjusted for rate as a linear function of RR interval; $\mathrm{QTa}=\mathrm{QT}-185 \times(\mathrm{RR}-1)$ for women with no BBB and QTa= QT $-157 \times(\mathrm{RR}$ $-1)-0.86 \times(\mathrm{QRS}$ duration-138) for women with BBB; and add $6 \mathrm{~ms}$ for men both in No-BBB and BBB groups.

HECG-LVH= Left ventricular hypertrophy by Cornell Voltage (RaVL $+\mathrm{SV} 3) \geq 2200 \mu \mathrm{V}$ for women and $\geq 2800 \mu \mathrm{V}$ for men with ECGs QRS duration $<120 \mathrm{~ms}$. 


\section{Table 2}

Hazard ratios with $95 \%$ confidence intervals for incident heart failure for dichotomized spatial and frontal QRS/T angles

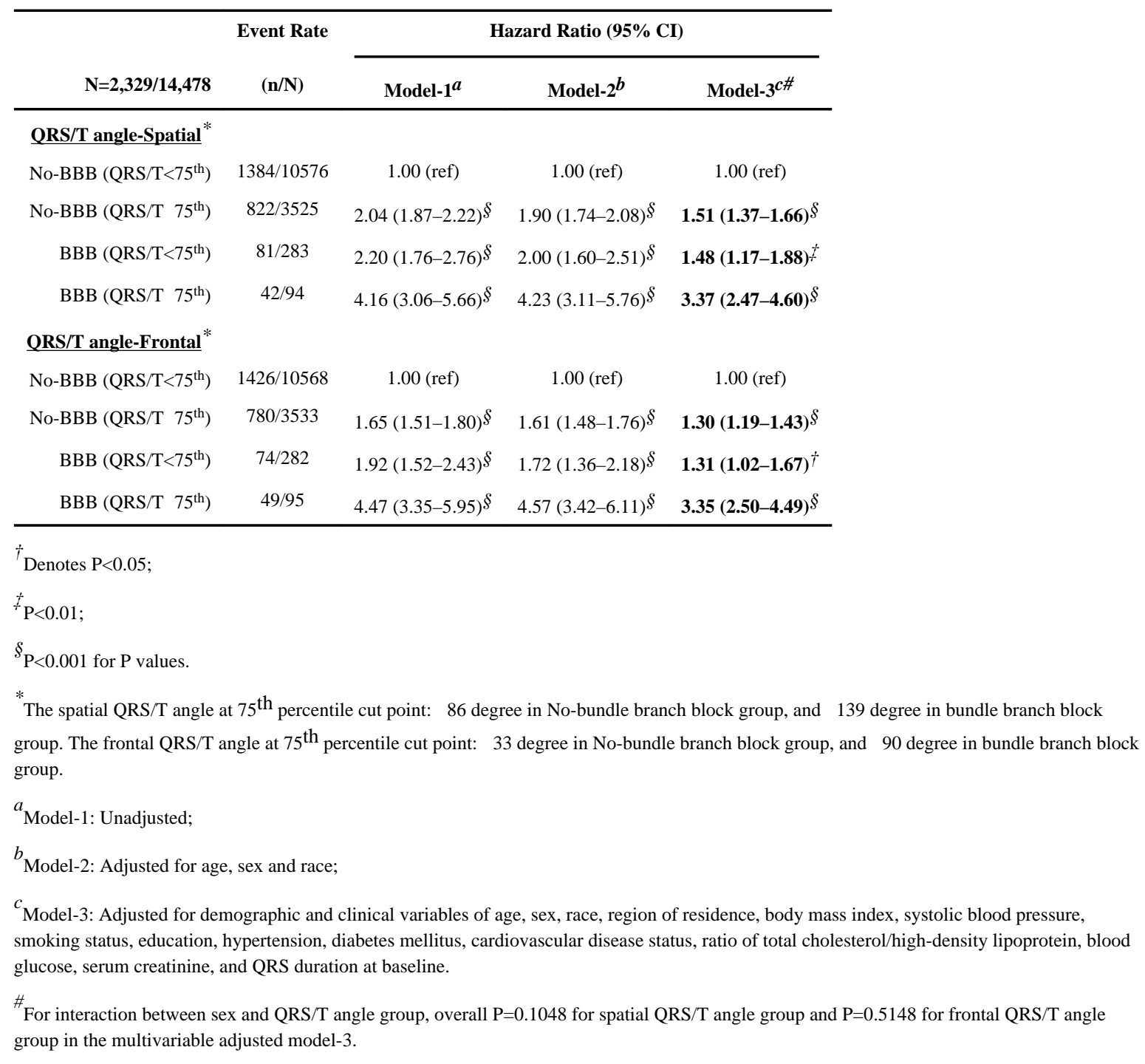




\section{Table 3}

Hazard ratios with 95\% confidence intervals for incident heart failure for spatial and frontal QRS/T angles by gender

\begin{tabular}{|c|c|c|c|c|}
\hline & \multicolumn{2}{|c|}{$\underline{\text { Events/1000 person years }}$} & \multicolumn{2}{|c|}{ Hazard Ratio $(95 \%$ confidence intervals $)$ ql } \\
\hline & Women & Men & Women $(\mathrm{N}=7901)$ & $\operatorname{Men}(N=6577)$ \\
\hline \multicolumn{5}{|l|}{$\underline{\text { QRS/T angle- Spatial }}{ }^{*}$} \\
\hline No-BBB (QRS/T<75 $\left.{ }^{\text {th }}\right)$ & 5.9 & 7.6 & 1.00 (ref) & 1.00 (ref) \\
\hline No-BBB (QRS/T $\left.\geq 75^{\text {th }}\right)$ & 11.1 & 15.9 & $1.45(1.27-1.65)^{\S}$ & $1.64(1.42-1.89) \S$ \\
\hline $\mathrm{BBB}\left(\mathrm{QRS} / \mathrm{T}<75^{\mathrm{th}}\right)$ & 16.0 & 17.3 & $2.03(1.36-3.02)^{\ddagger}$ & $1.44(1.05-1.95)^{\dagger}$ \\
\hline $\mathrm{BBB}\left(\mathrm{QRS} / \mathrm{T} \geq 5^{\mathrm{th}}\right)$ & 27.2 & 36.1 & $4.85(2.72-8.67)^{\S}$ & $3.17(2.15-4.68)^{\S}$ \\
\hline \multicolumn{5}{|l|}{ QRS/T angle- Frontal ${ }^{\#}$} \\
\hline No-BBB (QRS/T<75 $\left.{ }^{\text {th }}\right)$ & 6.1 & 7.8 & 1.00 (ref) & 1.00 (ref) \\
\hline No-BBB (QRS/T $\left.\geq 75^{\text {th }}\right)$ & 10.3 & 15.3 & $1.22(1.07-1.39)^{\ddagger}$ & $1.56(1.35-1.79)^{\S}$ \\
\hline $\mathrm{BBB}\left(\mathrm{QRS} / \mathrm{T}<75^{\mathrm{th}}\right)$ & 13.5 & 16.1 & $1.75(1.14-2.68)^{\dagger}$ & $1.40(1.03-1.90)^{\dagger}$ \\
\hline $\mathrm{BBB}\left(\mathrm{QRS} / \mathrm{T} \geq 5^{\mathrm{th}}\right)$ & 37.1 & 44.9 & $4.63(2.79-7.70)^{\S}$ & $3.29(2.21-4.90)^{\S}$ \\
\hline \multicolumn{5}{|l|}{ Denotes $\mathrm{P}<0.05$} \\
\hline \multicolumn{5}{|l|}{${ }_{\mathrm{P}}<0.01$} \\
\hline \multicolumn{5}{|l|}{$\S_{\mathrm{P}<0.001 \text { for } \mathrm{P} \text { values. }}$} \\
\hline \multicolumn{5}{|c|}{$\begin{array}{l}* \\
\text { The spatial QRS/T angle at } 75^{\text {th }} \text { percentile cut point: } \geq 9 \text { degree for men and } \geq 77 \text { degree for women in No-BBB group; and } \geq 134 \text { degree for me } \\
\text { and } \geq 145 \text { degree for women in BBB group. }\end{array}$} \\
\hline \multicolumn{5}{|c|}{$\begin{array}{l}\text { \# The frontal QRS/T angle at } 75^{\text {th }} \text { percentile cut point: } 235 \text { degree for men and } \geq 32 \text { degree for women in No-BBB group; and } \geq 85 \text { degree for men } \\
\text { and } \geq 105 \text { degree for women in BBB group. }\end{array}$} \\
\hline
\end{tabular}




\section{Table 4}

Hazard ratios with 95\% confidence intervals for incident heart failure for pooled bundle branch blocks and for right bundle branch block

\begin{tabular}{|c|c|c|c|c|}
\hline \multirow[b]{2}{*}{ Variable } & \multicolumn{2}{|c|}{ Pooled Bundle Branch Block ${ }^{\dagger}$} & \multicolumn{2}{|c|}{ Right Bundle Branch Block } \\
\hline & Cut Point & HR $(95 \% \mathrm{CI})^{\S}$ & Cut Point ${ }^{*}$ & HR $(95 \% \mathrm{CI})^{\S}$ \\
\hline (Event Rate) & & $(75 / 218)$ & & $(48 / 159)$ \\
\hline QRS/T angle-Spatial $\left({ }^{\circ}\right)$ & $\geq 147$ & $2.40(1.34-4.30)^{* *}$ & $\geq 111$ & $2.17(0.84-5.64)$ \\
\hline QRS/T angle-Frontal $\left({ }^{\circ}\right)$ & $\geq 123$ & $3.57(1.84-6.92)^{* *}$ & $\geq 55$ & $2.29(1.01-5.21)^{*}$ \\
\hline Heart rate (bpm) & $\geq 70$ & $2.43(1.30-4.54){ }^{* *}$ & $\geq 67$ & $1.03(0.46-2.30)$ \\
\hline QRS Duration (ms) & $\geq 130$ & $1.85(1.05-3.27)^{*}$ & $\geq 148$ & $0.80(0.34-1.89)$ \\
\hline //QTa (ms) & $\geq 452$ & $0.83(0.42-1.63)$ & $\geq 448$ & $2.18(0.99-4.78)$ \\
\hline \# $_{\text {STJ aVR }(\mu \mathrm{V})}$ & $\geq 14$ & $1.30(0.73-2.32)$ & $\geq 4$ & $0.77(0.33-1.80)$ \\
\hline STJ V1 $(\mu \mathrm{V})$ & $\geq 117$ & $1.44(0.71-2.93)$ & $\geq 68$ & $1.88(0.85-4.18)$ \\
\hline STJ V6 $(\mu \mathrm{V})$ & $\leq-20$ & $1.85(0.99-3.43)$ & $\leq-10$ & $1.73(0.79-3.81)$ \\
\hline${ }^{\#} \mathrm{~T}$ aVR $(\mu \mathrm{V})$ & $\geq 0$ & $2.03(1.13-3.65)^{*}$ & $\geq-161$ & $1.67(0.60-4.68)$ \\
\hline $\mathrm{T} \mathrm{V} 1(\mu \mathrm{V})$ & $\geq 468$ & $1.40(0.66-2.98)$ & $\geq-39$ & $1.70(0.61-4.75)$ \\
\hline T V6 $(\mu \mathrm{V})$ & $\leq-87$ & $1.54(0.84-2.80)$ & $\leq 136$ & $1.54(0.57-4.16)$ \\
\hline
\end{tabular}

* Denotes $\mathrm{P}<0.05$;

** $\mathrm{P}<0.01$;

P** $<0.001$.

${ }^{\dagger}$ Pooled BBB=bundle branch block excluding right bundle branch block.

* The cut point identifies the quartile 4 for the test group with quartiles 1-3 used as the reference group. Except for T wave amplitude and ST Jpoint depression in V6: quartiles 1 (decreased or more negative values) used as the test group and quartiles 2-4 as the reference group.

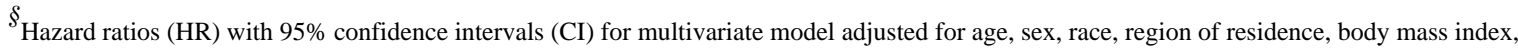
systolic blood pressure, smoking status, education, hypertension, diabetes mellitus, cardiovascular disease status, ratio of total cholesterol/highdensity lipoprotein, blood glucose, serum creatinine, and QRS duration at baseline.

"QTa for the QT interval adjusted for rate as a linear function of the RR interval.

${ }^{\text {\# }}$ ST and T refer to ST J-point and T wave amplitudes in leads aVR, V1 and V6. 